\title{
Review
}

\section{The shade-avoidance syndrome: multiple signals and ecological consequences}

\author{
Carlos L. Ballaré ${ }^{1,2}$ (D) \& Ronald Pierik ${ }^{3}$ (D) \\ ${ }^{1}$ IFEVA, Consejo Nacional de Investigaciones Científicas y Técnicas, Universidad de Buenos Aires, Ave. San Martín 4453C1417DSE \\ Buenos Aires, Argentina, ${ }^{2}$ IIB-INTECH, Consejo Nacional de Investigaciones Científicas y Técnicas, Universidad Nacional de San \\ Martín, B1650HMP Buenos Aires, Argentina and ${ }^{3}$ Plant Ecophysiology, Institute of Environmental Biology, Utrecht University, \\ Padualaan 8, 3584 CH, Utrecht, The Netherlands
}

\begin{abstract}
Plants use photoreceptor proteins to detect the proximity of other plants and to activate adaptive responses. Of these photoreceptors, phytochrome B (phyB), which is sensitive to changes in the red (R) to far-red (FR) ratio of sunlight, is the one that has been studied in greatest detail. The molecular connections between the proximity signal (low R:FR) and a model physiological response (increased elongation growth) have now been mapped in considerable detail in Arabidopsis seedlings. We briefty review our current understanding of these connections and discuss recent progress in establishing the roles of other photoreceptors in regulating growth-related pathways in response to competition cues. We also consider processes other than elongation that are controlled by photoreceptors and contribute to plant fitness under variable light conditions, including photoresponses that optimize the utilization of soil resources. In examining recent advances in the field, we highlight emerging roles of phyB as a major modulator of hormones related to plant immunity, in particular salicylic acid and jasmonic acid (JA). Recent attempts to manipulate connections between light signals and defence in Arabidopsis suggest that it might be possible to improve crop health at high planting densities by targeting links between phyB and $\mathbf{J A}$ signalling.
\end{abstract}

Key-words: light quality; shade; hormones; signalling; phytochrome; herbivory; pathogens; Jasmonate.

\section{INTRODUCTION}

During the last four decades there has been an enormous increase in our understanding of how plants sense shading and the proximity of neighbours and how they activate adaptive morphological and physiological responses. Research in the field has moved from working on simple morphological responses (e.g. internode elongation) to a single light cue [low red to far-red (R:FR) ratio] to the discovery of multiple responses elicited by a broad spectrum of neighbour proximity signals. Important elements of the signal transduction

Correspondence: C. L. Ballaré and R. Pierik. e-mail: ballare@ifeva.edu. ar; r.pierik@uu.nl pathways that connect informational photoreceptors with functional responses have been elucidated, and shade avoidance has become a textbook example of adaptive plasticity. In this review, we describe the progress in understanding shadeavoidance mechanisms, summarize our current view of the roles of different photoreceptors in the perception of competition and highlight the diversity of plant processes and functions that are controlled by canopy light signals. We also consider future challenges and opportunities in this multidisciplinary research field. Other reviews on this topic have been published recently and provide additional perspectives on the mechanisms and functional implications of shade-avoidance responses (Casal 2013; Ballaré 2014; Pierik \& de Wit 2014; Pierik \& Testerink 2014; de Wit et al. 2016a; Fraser et al. 2016; Viczian et al. 2016).

\section{PHYTOCHROME PERCEPTION OF CHANGES IN THE R:FR RATIO}

\section{Connecting shade with phytochrome}

As early as 1971, studies on cultivated tobacco revealed that the ratio between $\mathrm{R}(\lambda \sim 650 \mathrm{~nm})$ and $\mathrm{FR}(\lambda \sim 730 \mathrm{~nm})$ radiation was lower under the canopies than in direct sunlight and that plant treatment with FR radiation could promote stem elongation (Kasperbauer 1971). These studies inspired the pioneering work of H. Smith in the 1970s, describing the basics of shadelight perception and responses. Using a FR supplementation approach, it was found that the R:FR ratio was a key determinant of elongation growth in shade-intolerant species such as Chenopodium album and Sinapis alba. R light is absorbed by plants for photosynthesis, whereas FR radiation is mostly reflected or transmitted. Elegant studies revealed that internode elongation was strongly accelerated at low R:FR ratios (e.g. Morgan \& Smith 1978), a response that could be considered adaptive because it would allow the plant to position its leaves in higher, better-lit strata of the canopy (Fig. 1a). These effects of light quality on elongation were attributed to phytochrome, a R:FR-reversible protein discovered in the 1950 s by scientists working at the U.S. Department of Agriculture in Beltsville, MD (Hendricks \& Borthwick 1959) (for historigraphical accounts, see Sage 1992 and Lindblom 2015). Typically, phytochrome occurs in a photoequilibrium 

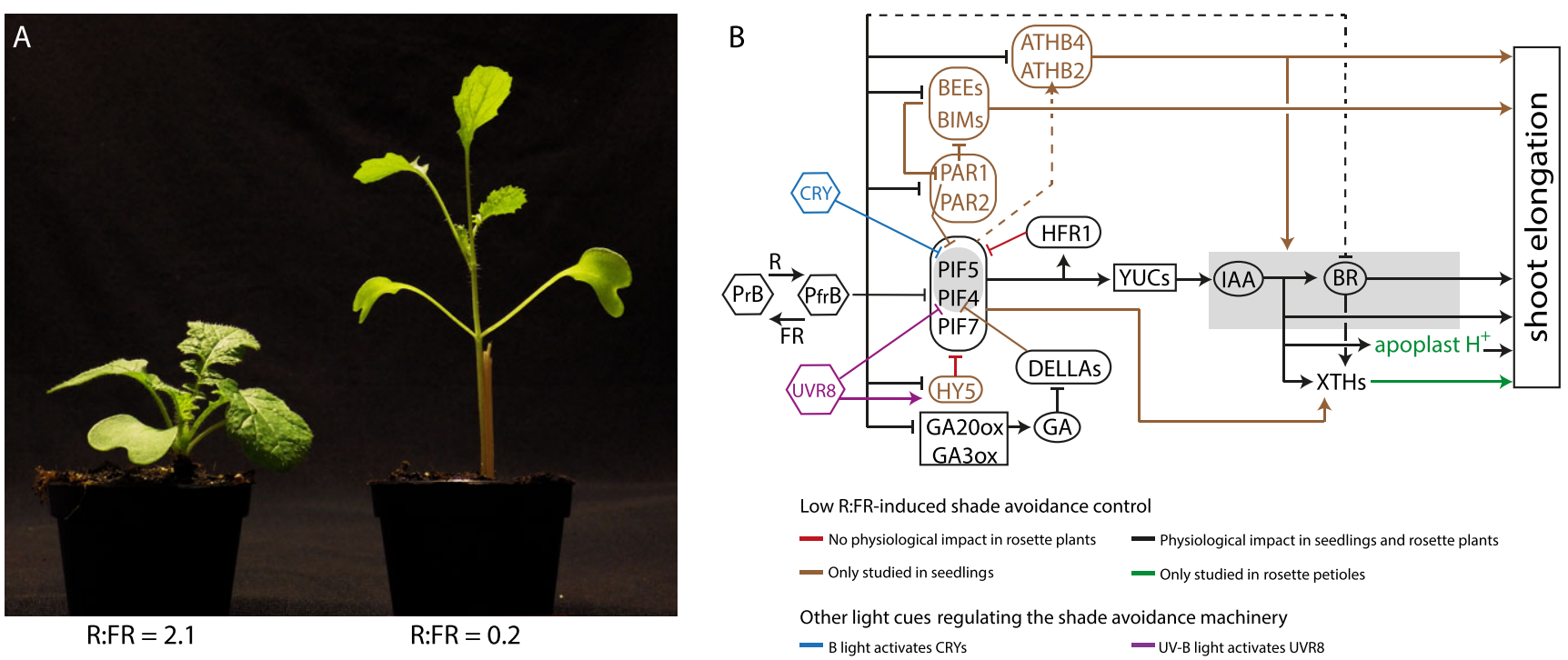

Figure 1. Photoreceptors regulate shade-avoidance responses. (a) Brassica nigra grown for 2 weeks in a growth chamber under white light (red to far-red $(\mathrm{R}: \mathrm{FR})=2.1$ ) or white light supplemented with FR $(\mathrm{R}: \mathrm{FR}=0.2)$. Low R:FR stimulates elongation of the hypocotyl, internodes and petioles, whereas the expansion of the leaf lamina is inhibited. Growth conditions: $9 \mathrm{~h}$ light (PAR $=150 \mu \mathrm{mol} \mathrm{m}^{-2} \mathrm{~s}^{-1}, 15 \mathrm{~h}$ light), RH=70\%, $\left.21^{\circ} \mathrm{C}\right) .(\mathrm{b})$ Schematic representation of the signal transduction network that regulates elongation responses under the control of phyB in Arabidopsis thaliana. UV-B signalling through UVR8 and blue light signalling through CRYs also feed into the core PIF signalling hub that orchestrates the majority of the downstream events. Different colours indicate study systems in which certain signal transduction components were shown to function in low R:FRinduced elongation. Rounded boxes, transcription (co)factors; square boxes, hormone biosynthetic enzymes; ellipses: hormones; hexagons: photoreceptors. The dashed lines indicate hypothesized mode of action. The arrows indicate positive interaction; the blocked arrows indicate negative interaction.

between the active (Pfr) and inactive (Pr) states. Absorption of R light converts Pr to Pfr, whereas FR absorption by the active Pfr form reverts it to the inactive Pr state. In addition to this R:FR photoreversibility, Pfr can spontaneously revert to the inactive Pr state by a slow non-photoinduced reaction (Li et al. 2011). Internode elongation rates of light-grown Chenopodium album and Sinapis alba seedlings were found to correlate very tightly with the phytochrome photoquilibrium, defined as Pfr/Ptotal (Morgan \& Smith 1978; Child and Smith, 1987). The early work of Smith and co-workers provided three key pieces of evidence to support the concept that the main function of phytochrome was to promote stem elongation under shade: (i) the R:FR ratio was an excellent signal of canopy cover; (ii) within the natural range of variation [between 1.2 (full sunlight) and 0.1 (deep shade)], changes in R:FR ratio are linearly related with changes in the estimated phytochrome photoequilibrium; and (iii) under experimental conditions, the rate of internode elongation is inversely related to the calculated Pfr/Ptotal ratio established by the light sources (Smith 1982). This work was followed by outdoor experiments in several systems that began to address the role of phytochrome in the perception of leaf shading and the ecological implications of plant responses to light quality under field conditions (Deregibus et al. 1985; Ballaré et al. 1987; Schmitt et al. 1995; Schmitt et al. 1999).

A particularly important aspect of R:FR dynamics during the growth of a plant stand is that the R:FR ratio of horizontally propagated light decreases before true shading among neighbouring plants occurs, owing to the backscattering of
FR radiation by green leaves (Ballaré et al. 1987). This reflection signal allows plants to remotely detect their neighbours and activate elongation responses before the onset of competition for resources (Ballaré et al. 1987; Ballaré et al. 1990). Laboratory experiments with linear variable displacement transducers indicated that internode elongation responses to FR-enrichment can occur very rapidly, within minutes upon FR exposure (Child \& Smith 1987), and canopy studies demonstrated that the internodes themselves are important sites of perception for reflected FR (Ballaré et al. 1989; Ballaré et al. 1990).

Subsequent research on shade avoidance demonstrated that not just internode or hypocotyl elongation are controlled by R: FR ratio but in fact a suite of responses, including petiole elongation, upward leaf movement (hyponasty), inhibition of branching and acceleration of flowering, are commonly coexpressed when phytochrome is inactivated. This suite of responses is collectively known as the shade-avoidance syndrome (SAS) (Smith 1995).

Multiple phytochromes sense changes in R:FR ratio (discussed in Smith \& Whitelam 1997), and although phytochrome B (phyB) is the predominant phytochrome controlling SAS in response to low R:FR ratio (Franklin \& Quail 2010) and neighbour proximity (Ballaré 1999), phyD and phyE seem to have partially redundant functions in Arabidopsis (Franklin \& Quail 2010). In young seedlings phyA partially antagonizes low R:FR-induced hypocotyl elongation, due to its activation by FR radiation. As phyA is light-labile, its involvement in fully de-etiolated, more mature plants is rather modest (Franklin \& Quail 2010). 


\section{The signalling network downstream of phytochromes}

A number of transcriptome surveys have been conducted on shade-avoidance responses in Arabidopsis. The first ones were published more than a decade ago, using the aerial parts of young Arabidopsis seedlings (Devlin et al. 2003; Salter et al. 2003), and were followed by studies that focused on more mature, rosette-stage plants and sampled specific organs (Kozuka et al. 2010; de Wit et al. 2013; de Wit et al. 2016b). Very recently, transcriptome surveys have been published that include detailed time series and between-organ comparisons of gene expression profiles (Das et al. 2016; Kohnen et al. 2016) and experiments that compare multiple light quality treatments (de Wit et al. 2016b). These transcriptome surveys have been useful to generate models of regulatory networks. Nevertheless, functional proof for causal involvement of specific regulators has come from dedicated physiological and gene functional studies, which in some cases were combined with transcriptome profiling of genotypes with perturbed expression or activity of the proposed signalling components (e.g. Tao et al. 2008; Hornitschek et al. 2012; Leivar et al. 2012; Li et al. 2012; Ciolfi et al. 2013; Pedmale et al. 2016; Procko et al. 2016).

An impressive variety of regulators downstream of phy photoconversion has been elucidated, mostly by studying the elongation response of Arabidopsis hypocotyls to supplemental FR irradiation under white light conditions (Fig. 1b). We will classify these regulators according to function and discuss them briefly.

\section{Phytochrome-interacting factors}

Phytochrome, upon activation by R light, migrates from the cytosol to the nucleus where it interacts with phytochromeinteracting factors (PIFs), a group of subfamily 15 of bHLH transcription factors (Leivar \& Quail 2011; Leivar \& Monte 2014). Although this family contains 7 members that can physically interact with phytochrome, only three of these phyinteracting proteins are unambiguously involved in SAS control: PIF4, PIF5 and PIF7. PIFs contain an active phytochrome-binding (APB) domain with which they interact specifically with the biologically active Pfr form of phyB, although PIF1 and PIF3 have been shown to also interact with Pfr from phyA through a motif called active phytochrome Abinding (APA) (Li et al. 2011). Upon interaction with phyB Pfr, PIFs typically are phosphorylated, and in the case of PIF4 and PIF5, they are subsequently ubiquitinated and degraded (Lorrain et al. 2008). In the case of PIF7, phosphorylation occurs but no subsequent degradation was observed, even though PIF7 ability to regulate transcription of target genes was inhibited (Li et al. 2012).

\section{Other transcriptional regulators}

Several other transcriptional regulators are controlled at the transcriptional level by phytochrome inactivation in low $\mathrm{R}$ : FR ratios (Fig. 1). Among these are other members of the bHLH family, such as HFR1, PAR1 and PAR2 (Sessa et al.
2005; Roig-Villanova et al. 2007). These three proteins are negative regulators that lack a typical basic domain to interact with promoters of target genes. Instead, they interact with the DNA binding domain of PIF proteins, preventing PIFs from interacting with the promoters of their target genes (Hornitschek et al. 2009; Galstyan et al. 2011). These regulators are thought to keep the strength of elongation responses in check. Indeed, $h f r 1$ knockout mutants have exaggerated low R:FR-induced hypocotyl elongation, whereas an overexpressor of a stable HFR1 protein has suppressed elongation (Galstyan et al. 2011). These studies have been limited to young seedlings, and the functionality of these negative regulators in mature plants remains to be verified. Other bHLH proteins whose gene expression is induced upon low R:FR ratio, but that are positive regulators of SAS, include BEE1 and BIM, which are PAR1-interacting factors (Cifuentes-Esquivel et al. 2013).

Transcription factors from families other than bHLHs that are induced upon exposure to low R:FR ratios include homeodomain-leucine zipper (HD-ZIP) proteins encoded by ATHB2, ATHB4, HAT1, HAT2 and HAT3 (Steindler et al. 1999; Sorin et al. 2009). ATHB2 diurnal expression under short-day conditions has been shown to be PIF4-dependent and PIF5-dependent (Kunihiro et al. 2011). ELONGATED HYPOCOTYL 5 (HY5) encodes a bZIP transcription factor that is up-regulated in response to low R:FR ratio (Ciolfi et al. 2013; de Wit et al. 2016b) (although HY5 protein stability is reduced by end-of-day FR; Toledo-Ortiz et al. 2014) and that can interact with PIFs (Chen et al. 2013), thereby inhibiting their function in a way that is similar to HFR1.

\section{Hormones}

The previously described transcription factor network is highly interconnected, and novel components and interactions are still being elucidated. This network, largely centred around PIFs (Fig. 1), is now known to target some major physiological regulatory components, particularly hormones. Upon exposure to low R:FR ratios, the biosynthesis of at least three growthassociated hormones is stimulated: gibberellins (GA), auxin and ethylene. In addition, low R:FR desensitizes plants to defence-associated plant hormones, such as jasmonic acid (JA) and salicylic acid (SA), which leads to a crosstalk between shade avoidance and plant immunity that will be discussed in the sections 'Effects on biotic interactions' and 'Growth-defence balance'.

Auxin is now known as the dominant physiological regulator activated by PIF proteins when they accumulate in low R:FR light. Low R:FR-induced auxin is derived from tryptophan through the TAA1 pathway (Tao et al. 2008) and involves PIF-mediated transcription of YUCCA genes that encode rate-limiting enzymes in auxin biosynthesis (Hornitschek et al. 2012; Li et al. 2012). This low R:FR-induced de novo synthesis of auxin in seedlings occurs mostly in the cotyledons (Procko et al. 2014) and drives expression and localization of the auxin efflux-associated protein PIN3 to transport auxin towards the hypocotyl epidermis (Keuskamp et al. 2010). In the epidermis auxin induces both brassinosteroid (BR)-dependent 
and BR-independent responses (Procko et al. 2016). Auxin signalling through the receptor TIR1 and related Auxin Signalling F-Box Proteins (AFBs) leads to degradation of AUX/IAA proteins, which in turn relieves repression of auxin response factors (ARFs) that control transcription of auxin response genes, ultimately leading to cell growth (reviewed in Dünser \& Kleine-Vehn 2015).

Low R:FR conditions also stimulate the biosynthesis of another group of growth-promoting hormones: GA. This occurs at least in part through transcriptional up-regulation of genes encoding the GA biosynthetic enzymes GA20ox1 and GA20ox2 (Hisamatsu et al. 2005). Bioactive GA, upon interacting with its receptor GID1, leads to ubiquitination and subsequent proteasomal degradation of DELLA proteins, GRAS domain proteins that lack direct DNA binding properties (Harberd et al. 2009). Interestingly, DELLAs are direct interactors of PIFs (de Lucas et al. 2008; Feng et al. 2008) and their binding to PIFs prevents PIF proteins from binding DNA and thus controlling the expression of growth-promoting genes. Low R:FR ratios promote DELLA degradation (Djakovic-Petrovic et al. 2007; Leone et al. 2014), and proteins that physically interact with DELLAs, such as BBX24, were shown to modulate DELLA-mediated repression of PIF activity and shade-avoidance responses (Crocco et al. 2015).

Finally, biosynthesis of the volatile hormone ethylene is accelerated upon phytochrome inactivation in low R:FR light (reviewed in Kegge \& Pierik 2010). Cultivated tobacco plants expressing the dominant negative mutant receptor etr1-1 from Arabidopsis are ethylene-insensitive and show delayed shadeavoidance responses to plant neighbours at high density (Pierik et al. 2004a). Although there is an interaction with R:FR signalling (Pierik et al. 2004a), the delayed leaf movement and stem elongation responses to neighbours seem to be particularly associated with other canopy signals (Pierik et al. 2004b), which will be discussed in the succeeding texts.

\section{Actuators in growth control}

The previously described plethora of transcription factors, transcriptional co-regulators, hormone biosynthesis enzymes and hormone signalling components ultimately target the cell growth machinery. Shade-avoidance research has mostly focused on cell expansion as the driving force of organ elongation. For plant cells to expand, they need to loosen their cell walls so they can yield to the existing turgor pressure from the vacuoles. Indeed, an established shade-avoidance marker gene that is under R:FR control is XTH15/XTR7 (Hornitschek et al. 2009; de Wit et al. 2012). XYLOGLUCAN ENDOTRANSGLUCOSYLASE/HYDROLASE (XTH) proteins are cell wall modifying enzymes that can modify the load-bearing xyloglucan-cellulose cross links in the cell wall. Cleavage through hydrolase activity results in wall loosening, whereas transglucosylation can strengthen the cell wall, thus giving these proteins the potential to control cell growth (Rose et al. 2002; Sasidharan et al. 2011). It has been shown that PIFs can directly target the expression of, for example, XTH15 in Arabidopsis seedlings under low R:FR ratios (Hornitschek et al. 2009). Furthermore, coordinated auxin production and polar auxin transport has also been shown to be important for enhanced expression of different XTHs (e.g. XTH17 and XTH19) in Arabidopsis petioles under shade (Sasidharan et al. 2014). Interestingly, auxin involvement in shade-induced $X T H$ expression intersects with another component of cell growth: cortical microtubules (CMTs) (Yu et al. 2015). CMTs rearrange their subcellular localization in shade, facilitating unidirectional cell growth in Arabidopsis petioles and disrupting CMT polymers with the drug oryzalin inhibits shade-induced petiole elongation. CMT disruption also minimizes shade-induced expression of some XTHs, and this can be rescued by exogenous application of auxin (Sasidharan et al. 2014). Finally, the classic mode of action for auxin-induced cell growth is the acid growth theory: auxin regulates activity of proton pumps in the plasma membrane, leading to acidification of the apoplast, thereby increasing, among others, the activity of cell wall modifying proteins (reviewed in Dünser \& KleineVehn 2015).

\section{MULTIPLE SIGNALS FOR SHADE AND NEIGHBOUR DETECTION}

The R:FR ratio is an incredibly reliable indicator of plant proximity as very few objects other than green plants absorb R light so efficiently and FR barely at all. Perhaps because the signal appeared to be so good, shade-avoidance research has focused for many years almost exclusively on phytochrome signalling of changes in R:FR ratio (Ballaré 1999). Nevertheless, there is now strong evidence that other signals play an important role activating shade-avoidance responses in plant canopies. Most of these signals are generated from the spectral properties of leaves, which include strong absorption of R, blue and ultraviolet (UV) radiation and reflection and transmission of green and especially FR radiation. The emerging picture is that different light signals interactively control shade avoidance, thus adjusting the magnitude of the response to the severity of the competitive threat.

\section{Light intensity}

Although dismissed as 'essentially irrelevant' in an influential Commentary in this journal (Smith \& Whitelam 1997), attenuation of overall light intensity is now known to indeed induce shade-avoidance responses. One reason for the initial dismissal of light intensity (irradiance) as a shade signal could be that, under conditions in which light is limiting for photosynthesis (as was the case in many growth-chamber studies), the trophic effects and the photomorphogenic effects of light attenuation could have been confounded. Consistent with this hypothesis, in studies where shading was applied from the side, simulating the proximity of other plants but without affecting the light received by the leaves, attenuation of the light received by the internodes caused strong elongation responses (Ballaré et al. 1991). Another reason for not considering total irradiance as a shade signal was that shade-avoidance research at that time was rather 'elongation-centred', whereas especially leaf angles are highly responsive to changes in light intensity (Pierik et al. 
2004b; Mullen et al. 2006; Millenaar et al. 2009). The effects of attenuated light intensity promoting shoot elongation are partially mediated by cryptochromes (as discussed in the following section). However, early studies have shown that attenuation of $\mathrm{R}$ and FR radiation (without affecting blue light or the R:FR ratio) is sufficient to promote stem elongation in some species (Ballaré et al. 1991). The available evidence suggests that this irradiance response is mediated by phyB in Arabidopsis (Trupkin et al. 2014).

Interestingly, leaf responses that may contribute to shade tolerance, rather than avoidance, including the increase in specific leaf area (SLA), are strongly sensitive to changes in the intensity of photosynthetically active radiation (PAR) (Björkman 1981) but poorly responsive to changes in R:FR ratio (Poorter et al., 2012). Essentially, a higher SLA indicates a larger area to intercept solar radiation per unit carbon invested in the construction of leaf tissue, often coinciding with a thinner leaf through formation of fewer mesophyll cell layers.

\section{Blue light}

Blue light depletion can trigger shade-avoidance responses in many plant species. Perhaps, the best studied shade-avoidance response controlled by blue light is phototropism, which is mediated by phototropins (phot1 and phot 2 in Arabidopsis) (Briggs \& Christie 2002). Positive phototropism to blue light, along with negative phototropic responses to reflected FR radiation (Ballaré et al. 1992), can help plants to direct their growth toward canopy gaps in patchy canopies (Ballaré et al. 1995b; Ballaré 1999). Interestingly, in Arabidopsis seedlings, photmediated phototropism is enhanced by low R:FR ratios (Goyal et al. 2016).

Internode and petiole elongation in species such as tobacco, jimsonweed, mustard and Arabidopsis are also stimulated by the attenuation of blue light (Ballaré et al. 1991; Pierik et al. 2004b; Sellaro et al. 2010; Keller et al. 2011; Keuskamp et al. 2011). Exposure of light-grown Arabidopsis seedlings to light deprived of the blue component leads to a very strong elongation response of the hypocotyl, even larger than that induced by low R:FR (Pierik et al. 2009). This and other elongation responses to blue light depletion are triggered through the photoreceptors crytochrome 1 and 2 (cry1 and cry2) in Arabidopsis (Pierik et al. 2009; Keller et al. 2011; Pedmale et al. 2016). Low blue and low R:FR signalling recruit partially similar physiological regulators to control hypocotyls elongation, including auxin, BRs and XTHs (Keuskamp et al. 2011) (Fig. 1). Interestingly, also upstream of the hormones, low blue and low R: FR signalling were recently shown to converge in their requirement of transcriptions factors PIF4 and PIF5 (Keller et al. 2011). Pedmale et al. (2016) showed that cry 1 and cry2 interact physically with PIF4 and PIF5, thereby modulating their transcriptional output and hence growth, involving XTHs. The main difference between low R:FR ratio and low blue light seems to be that low R:FR-mediated hypocotyl elongation involves a dominant role for PIF7, with the pif7 knockout being essentially irresponsive to low R: FR ( $\mathrm{Li}$ et al. 2012), whereas the pif7 mutant still shows pronounced low blue-mediated elongation (Pedmale et al. 2016). Although blue light depletion induces shadeavoidance responses, depletion of blue light will not occur alone in dense vegetation (Ballaré et al. 1991). The functional relevance of blue light signalling in the control of shade avoidance seems to be that low blue levels enhance the elongation responses induced by low R:FR ratios, thus allowing plants to attune their shade-avoidance phenotype to the severity of competitive threat. This enhancement appears to occur through suppression by blue light depletion of negative SAS regulators, such as HFR1, which are induced by low R:FR conditions (de Wit et al. 2016b).

\section{UV-B radiation}

Plant canopies effectively filter out UV radiation, including the UV-B (290-315 nm) component (Flint \& Caldwell 1998), and changes in UV-B levels can affect plant growth. Inhibition of hypocotyl elongation by UV-B radiation involves the UV-B receptor UVR8 in Arabidopsis (reviewed in Jenkins 2009 and Ulm \& Jenkins 2015). UVR8 binds to CONSTITUTIVELY PHOTOMORPHOGENIC 1 (COP1), thereby promoting accumulation of HY5 and HY5 HOMOLOGUE (HYH) (Brown \& Jenkins 2008; Favory et al. 2009). HY5/HYH promote GA degradation, leading to stabilization of growth-repressing DELLA proteins and inhibiting PIF function. UV-B also enhances the degradation of PIF4 and PIF5 (Hayes et al. 2014). Consequently, PIF and auxin-dependent elongation responses to low R:FR ratio can be antagonized by the UVR8-dependent signalling of UV-B radiation (Hayes et al. 2014; Mazza \& Ballaré 2015).

\section{Non-light cues}

Although canopy-generated light cues probably dominate neighbour detection and shade avoidance, some complementary signalling mechanisms have been described. It was found in Arabidopsis canopies that the flat lying rosette leaves do not generate a strong FR-reflection signal, due to the absence of a vertical structure. As a consequence, these plants detect neighbours through touching of neighbouring leaf tips. In response to this biomechanical detection, Arabidopsis leaves move upward, thereby creating a vertical structure that generates horizontal FR reflection, thus triggering low R:FR responses in the stand, such as petiole elongation (de Wit et al. 2012). The regulatory (sensing) mechanisms underpinning these responses are currently unknown, but seem to differ from other established thigmomorphogenic responses (Chehab et al. 2009; Chehab et al. 2012).

Plants in high-density stands can be close enough to communicate via volatile compounds. Much has been written about volatile organic compounds (VOCs) and their potential for carrying information about neighbour identity and physiological status. As mentioned earlier, ethylene emissions are largely increased under low R:FR light. and it has been shown that ethylene can accumulate to physiologically meaningful concentrations in dense stands of cultivated tobacco (Pierik et al. 2004b). Although the emission of several other volatiles 
from Arabidopsis (Kegge et al. 2013), barley (Kegge et al. 2015) and tomato (Cortés et al. 2016) are affected by low $\mathrm{R}: \mathrm{FR}$ ratios, it remains to be studied if these changes in VOC profiles are involved in neighbour detection and shade-avoidance responses. Nevertheless, it has been shown that the changes in VOC emissions induced by low R:FR in barley can alter carbon allocation in neighbouring plants (Kegge et al. 2015).

\section{FROM MORPHOLOGY TO MULTIPLE RESPONSES}

The initial focus on stem elongation responses led to a detailed mechanistic understanding of the molecular connections between photoreceptors, particularly phyB and growthrelated signalling pathways (Fig. 1). Photoreceptors provide information on neighbour proximity and spatial distribution, thereby allowing the plant to 'forage' for light in complex canopies. It is now becoming clear that proximity perception leads to a complete reconfiguration of plant function. This reconfiguration allows the plant to optimize the deployment of leaves into light gaps, balance resource allocation between shoots and roots, optimize leaf gas exchange and nutrient uptake as a function of the degree of shading and adaptively regulate interactions with herbivores, pathogens and beneficial microorganisms (Fig. 2).

\section{Optimizing resource capture and economy}

The roles of phyB and other photoreceptors, including phototropins and cryptochromes, as modulators of morphological responses that are important for the optimization of leaf placement in patchy canopies are now well documented and have been summarized in previous sections of this review. Field studies have shown that mutants impaired in R: FR perception are less efficient than the corresponding wild types at foraging for light in heterogeneous light environments, providing direct evidence for the adaptive value of phytochrome-mediated shade avoidance (Ballaré et al. 1995b; Schmitt et al. 1995; Schmitt et al. 1999). More recent work has suggested that in addition to the main functions of phytochromes, cryptochromes and phototropins in controlling shoot architecture and foraging for light in patchy canopies, the UV-B photoreceptor UVR8 may contribute to attenuate shade-avoidance responses when the plant meets well-illuminated areas in canopy gaps (Hayes et al. 2014; Mazza \& Ballaré 2015).

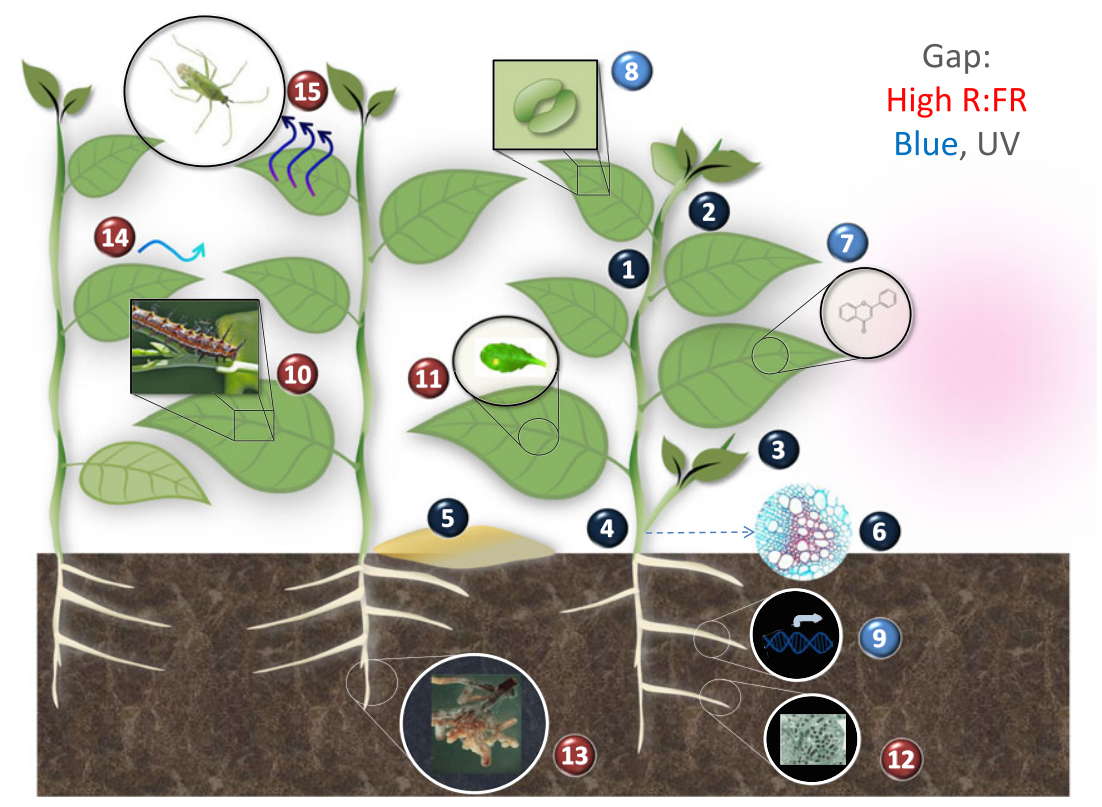

Figure 2. Photoreceptors optimize plant structure and function in patchy canopies. As discussed in the text, proximity cues perceived by phyB and other photoreceptors are used by the plant to optimize foraging for light, as these signals regulate stem elongation (1); phototropism (2); branching (3); resource partitioning between shoot and roots (4); and leaf senescence (5). In addition to these structural changes that allow the plant to optimize the spatial distribution of its branches and leaves in the canopy light matrix, photoreceptors regulate the mechanical strength and hydraulic resistance of the stem (6) and contribute to adjust the physiology of resource-harvesting organs to the prevailing light conditions. Under high light, such in a canopy gap, photoreceptors activate leaf photoprotection (7), increase stomatal conductance and sensitivity to water stress signals (8) and activate mobile signals that increase the expression of a $\mathrm{NO}_{3}^{-}$transporter in the roots (9), which presumably contributes to maintain the C:N homeostasis under changing light conditions. Proximity signals perceived by phyB also have profound effects on plant interactions with other organisms. Low R:FR ratios locally repress jasmonic acid signalling and down-regulate salicylic acid responses, which reduces plant resistance to herbivores (10) and pathogens (11). Light effects on jasmonate signalling also affect plant interactions with root simbionts, including rizhobia (12) and mycorrhyzae (13). Low R:FR ratios also promote the emission of ethylene, which may contribute to shade avoidance (14) and alter the blend of terpene compounds emitted by induced plants, which may contribute to increase indirect defence against herbivores in shaded plants (15). 
Besides optimizing light interception, evidence is emerging that photoreceptors play a key role adjusting plant structure, hydraulics and nutrient uptake. In this section, we provide examples of the role of informational photoreceptors in controlling plant functional acclimation to open or shaded conditions. Transition between sun and shade are often associated with sharp variations in exposure to mechanical stress from exposure to wind, evaporative demand, nutrient requirements and need of photoprotection.

\section{Structural acclimation}

Early work in cucumber demonstrated that in canopy openings, activation of phyB promotes morphological and anatomical changes that increase plant fitness (Casal et al. 1994). Thus, when phyB is activated under sunlight conditions, $\mathrm{Pfr}$ promotes the formation of thicker and mechanically more resistant stems, with increased cross section of xylem vessels and higher water conductivity compared with plants under shade. These responses were shown to be essential for plant survival in canopy gaps (Casal et al. 1994). Effects of phyB on structural properties of the stems likely complement the specific effects of mechanical stress on internode architecture and mechanical resistance (Anten et al. 2005).

\section{Root function, uptake of soil resources and nutrient metabolism}

Root growth (Casal et al. 1994), gravitropism (Galen et al. 2007; Boccalandro et al. 2008) and development (Salisbury et al. 2007; Tong et al. 2008) are known to be affected by photoreceptors. Some of the effects of photoreceptors on root growth, particularly during de-etiolation, are thought to be mediated by changes in photoassimilate supply from the cotyledons, which is affected by photoreceptor signals that trigger cotyledon expansion and the establishment of photosynthetic competence in the shoot as it emerges from soil (Kircher \& Schopfer 2012). The adaptive value of root responses to photoreceptor signals has seldom been tested in the field (Gundel et al. 2014). However, there is some evidence that root foraging for soil resources can be influenced by photoreceptors. For example, Galen et al. (2007) demonstrated that the ability of Arabidopsis roots to forage for water in the field was impaired in a phot-1 mutant. Root cells have photoreceptors, but aside from the case of very young seedlings, where physiologically significant amounts of light can be piped from shoot to roots (Lee et al. 2016), or under certain types of substrates, such as very sandy soils (Tester \& Morris 1987), the vast majority of root cells will grow in the dark under field conditions. Therefore, most effects of light on root function are likely to depend on light perception by shoot cells and mobile signals traveling from shoot to roots. Recent research (Chen et al. 2016) demonstrated that HY5, a transcription factor involved in the signal transduction pathways of nearly all photoreceptors, is a signal that moves from shoot to root and mediates light promotion of root growth and nitrate uptake in Arabidopsis seedlings. Thus, shoot-derived HY5 activates HY5 expression in the root and promotes nitrate uptake by activating NRT2.1, a gene that encodes a high-affinity nitrate transporter. In the shoot, HY5 promotes the expression of genes involved in carbon assimilation and translocation to roots (Toledo-Ortiz et al. 2014; Chen et al. 2016), whereas in the root, HY5 activation of NRT2.1 expression and nitrate uptake is potentiated by increased sucrose levels (Chen et al. 2016). HY5 function is irradiance-dependent, and this regulation appears to play an important role, along with shoot-derived sugar signals (e.g. Kircher \& Schopfer 2012), in coupling nitrogen and carbon assimilation under variable light conditions (Chen et al. 2016). Photoreceptors also modulate nutrient metabolism and redistribution, for example during shade-induced leaf senescence. The activity of nitrate reductase, a key enzyme in nitrogen assimilation, is regulated by phytochrome (Whitelam \& Johnson 1980), and this regulation, among other metabolic changes, such as chlorophyll degradation, may contribute to optimize the redistribution of nutrient utilisation and photosynthetic capacity throughout the plant, so as to match the vertical light gradient in high-density crops (Rousseaux et al. 1996; Rousseaux et al. 1997).

\section{Regulation of stomatal conductance}

Gas exchange per unit leaf area is also regulated by photoreceptors, presumably contributing to optimize $\mathrm{CO}_{2}$ fixation under fluctuating light conditions. phyB controls stomatal differentiation (Casson et al. 2009; Kang et al. 2009), increasing stomatal density under open conditions (Boccalandro et al. 2009). This developmental response helps to minimize epidermal resistance to $\mathrm{CO}_{2}$ diffusion between the atmosphere and the mesophyll in leaves exposed to high irradiance (where light is not limiting for photosynthesis). However, the increased number of stomata could also make the plant more vulnerable to desiccation. This is, however, prevented by a positive effect of phyB on stomatal sensitivity to abscisic acid (González et al. 2012). Blue light photoreceptors, including phot1 and phot 2 and cry1 and cry2, may also be important to optimize photosynthesis under high irradiance, acting through mechanisms that are dependent or independent of stomatal responses (Boccalandro et al. 2012).

\section{Optimizing leaf photoprotection}

Adjusting photoprotection as a function of light exposure is also an important function of photoreceptors. Positioning of leaves in well-illuminated areas of the canopy during shade avoidance increases the availability of energy for photosynthesis, but at the same time increases the potential for harmful effects of UV radiation. Accumulation of protective phenolic sunscreens in the field is sensitive to small variations in the UV-B region of the solar spectrum (Barnes et al. 2000; Mazza et al. 2000), and the UV-B photoreceptor UVR8 has been shown to regulate the expression of numerous genes involved 
in the biosynthesis of these protective compounds (reviewed in Jenkins 2009 and Ulm \& Jenkins 2015). Under field conditions, other photoreceptors, besides UVR8, are likely to participate in the control of UV photoprotection (Morales et al. 2013). The accumulation of epidermal sunscreens is coordinated with growth inhibition responses (Ballaré et al. 1995a) and dynamically adjusted under fluctuating light conditions to maximize photoprotection (Barnes et al. 2016a; Barnes et al. 2016b).

\section{Effects on biotic interactions}

Recent studies have demonstrated that plant functional responses to proximity signals can impact plant interactions not only with other plants (i.e. competition) but also with a variety of other organisms, including herbivores, pathogens, symbionts and herbivore predators.

\section{Interactions with enemies}

A flurry of recent research has demonstrated that low R:FR ratios down-regulate defence responses in shade-intolerant species (reviewed in Ballaré 2014). Inactivation of phyB leads to increased susceptibility to insect herbivores and microbial pathogens of various lifestyles. This increased plant susceptibility to pathogens and herbivores has been linked to reduced expression of defence-related traits, including phenolic compounds (Izaguirre et al. 2006; Moreno et al. 2009), glucosinolates (Engelen-Eigles et al. 2006; Cargnel et al. 2014), latex (Agrawal et al. 2012) and extrafloral nectar (Izaguirre et al. 2013).

The observed reduction of defence responses can be explained by simultaneous attenuation, under low R:FR ratios, of the two major hormonal pathways that orchestrate plant defence, namely the SA and JA signalling pathways (reviewed in Ballare 2014). The mechanisms that mediate the effects of phyB inactivation on SA signalling are not well understood. Reduced induction of SA synthesis (Griebel \& Zeier 2008) and response to SA (de Wit et al. 2013) have been documented under conditions of phyB inactivation, and attenuation of SA under low R:FR ratios correlated with reduced levels of phosphorylation of the SA-signalling component NONEXPRESSOR of PATHOGENESIS-RELATED GENE 1 (NPR1) (de Wit et al. 2013). In the case of JA responses, shading has been shown to reduce herbivory-induced JA accumulation (Agrawal et al. 2012), and inactivation of phyB consistently reduces plant sensitivity to exogenous JA (Moreno et al. 2009; Cerrudo et al. 2012; de Wit et al. 2013). Sensitivity to JA under low R:FR ratios is attenuated as a consequence of increased turnover of DELLA proteins (presumably in response to increased GA activity) (Leone et al. 2014) and increased stability of jasmonate ZIM domain (JAZ) repressor proteins (Chico et al. 2014; Leone et al. 2014). Destabilization of MYC transcription factors in response to low R:FR may also contribute to attenuating defence responses (Chico et al. 2014). Physical interaction (and mutual interference) between the growth-repressing DELLA proteins and defence-repressing JAZ proteins is thought to be critical in the regulation of resource allocation between growth and immunity (Hou et al.
2010; Yang et al. 2012). Therefore, the ability of phyB to affect the stability of members of these two protein families represents a critical link between the photoperception of neighbour proximity and the transcriptional programmes that optimize resource allocation between shade-avoidance and defence responses under variable conditions of competition (Ballaré 2014; Mazza \& Ballaré 2015).

\section{Interactions with beneficial microorganisms}

There is growing evidence that photoreceptors, particularly phyB, can regulate plant interactions in the rizosphere. Plant nutrition is often dependent on associations between roots and beneficial microorganisms, such as nitrogen-fixing bacteria, and mycorrhizae. Early studies have demonstrated that these symbiotic associations are modulated by light quality (reviewed by Gundel et al. 2014). For example, supplemental FR radiation perceived by the shoots reduces nodulation in legumes (Kasperbauer et al. 1984; Kasperbauer \& Hunt 1994). Similarly, simulated canopy shade reduces mycorrhizal colonization in several plant species (de la Rosa et al. 1998; Skálová \& Vosátka 1998; Pecháčková 1999). The development of symbiosis and the subsequent maintenance of the symbiont represent a metabolic cost to the host plant, and the exchange of carbon for nutrients between plants and root symbionts is tightly regulated (Helber et al. 2011). Therefore, it is reasonable to expect that photoreceptors that inform the plant about the prevailing light conditions (and hence the conditions for carbon assimilation) have a role modulating the establishment and symbiotic interactions. Recent work suggests that the positive effects of phyB on legume-Rhizobium interactions is mediated by enhanced JA signalling (Suzuki et al. 2011). Similarly, the positive effects of high R:FR ratios and phyB on colonization of tomato and Lotus japonicas roots by arbuscular mycorrhizae correlate with enhanced expression of JA markers in the roots and increased concentrations in the root exudates of (+)-5deoxystrigol, a strigolactone that functions as an inducer of fungal hyphal branching (Nagata et al. 2015).

\section{GROWTH-DEFENCE BALANCE}

The demonstration that, in addition to the well-known effects on growth-related processes, photoreceptors are key regulators of plant immunity has lent support to the idea that these proteins have an important role in balancing allocation between growth and defence (discussed in Ballaré 2014). When shade-intolerant plants are simultaneously challenged with competition and herbivory or pathogen attack, foraging for light through growth responses often takes priority over plant immune responses.

Short-term studies with Arabidopsis demonstrate that it is possible to genetically uncouple the effects of light on growth from the effects of light on defence. For example, the sav3 mutant of Arabidopsis, which does not respond to supplemental FR radiation with increased leaf elongation and the classic repertoire of changes in shoot morphology, still displays a low defence phenotype in bioassays (Moreno et al. 2009; Cerrudo et al. 2012). Conversely, the cry1 mutant, which shows a constitutively elongated phenotype under white light, does not 
display increased susceptibility to infection by the fungus Botrytis cinerea (Cerrudo et al. 2012). More importantly, by mutating $J A Z$ genes it has been possible to keep defenses at high levels in plants that express a classic SAS morphological repertoire in response to phyB inactivation (Cerrudo et al. 2012; Leone et al. 2014; Campos et al. 2016; Cerrudo et al. 2017).

The demonstration in Arabidopsis that it is possible to experimentally uncouple the effects of light on growth from the effects of light on defence indicate that at least in the short term, plants are able to defend their tissues from consumer organisms even if they are committing resources to express shade-avoidance responses to outcompete their neighbours. At the same time, these observations beg the question of why, then, do plants normally repress their defenses when they face a high risk of competition? A possible explanation is that it is advantageous for the plant to make the decision of curtailing expenditures in defence while it still has plenty of resources. Unlike escape responses in animals, which can be very rapid, escaping from competition in plants often requires new growth, which could be slow and demanding in terms of carbon and other resources. Therefore, rapid use of information about neighbour proximity in the mechanisms that control resource allocation might be very important for plants that grow in competitive environments. It is also worth noting that plants appear to have evolved strategies to minimize the fitness costs of down-regulating defenses in response to competition signals. As explained in the succeeding texts, these strategies take advantage of the modular nature of the plant body and the complex biotic scenario in which plants interact with their attackers.

\section{Shrewd allocation}

Plants are modular organisms, and as such they can save resources by activating defence responses only in their most valuable modules. Not all plant parts have the same importance for the capture of resources. For example, those leaves that are placed in well-illuminated strata of the plant canopy have a high potential to contribute to the carbon balance of the plant. In contrast, leaves that become shaded have a relatively low value and will eventually activate a senescence programme leading to leaf abscission. Whereas the induction of defence in response to attack is generally systemic (Ross 1961; Green \& Ryan 1972), the repression of defence responses by photoreceptor signals appears to be localized (Izaguirre et al. 2013). In Passiflora edulis plants, wounding and MeJA treatment activated the systemic production of extrafloral nectar (an indirect defence), and this response could be suppressed locally in individual branches by supplementing the light received by those branches with FR radiation (Izaguirre et al. 2013). This suggests that when activating a defence programme in response to attack, the plant can, because of its modular organization, 'sacrifice' those modules that encountered poor or not so promising light conditions and concentrate its defence resources in the most valuable parts of the organism. The assignment of 'value' to the different plant parts for this self-pruning strategy could be based on phyB status (where high Pfr levels would mean favorable light conditions), as in the $P$. edulis case.
However, under natural conditions, other physiological differences between sun and shade branches may contribute to locally adjust the expression of the defence response. One of these additional signals could be the level of cytokinins (discussed in Ballaré 2014). Cytokinins are positive regulators of defence and JA responses (Choi et al. 2010; Dervinis et al. 2010; Brütting et al. 2017), and because of their higher transpiration rates, sun leaves have higher levels of cytokinins than shaded leaves (Boonman et al. 2007).

\section{Calling for help}

Low R:FR ratios can alter the emission of constitutive and JAinduced VOCs in Arabidopsis, and these changes can be perceived by herbivorous insects (Kegge et al. 2013). A recent study suggested that shifts in the blend of VOCs induced by phyB inactivation could play an important role in the attraction of predatory insects. Working with tomato, Cortés et al. (2016) found that when phyB was inactivated (by mutation or supplemental FR), leaf defenses were down-regulated, as expected; however, at the same time, phyB inactivation led the plants to produce a blend of JA-induced monoterpenes that increased their attractiveness to the predatory mirid bug Macrolopus pigmaeus (Cortés et al. 2016). This predator can provide indirect protection to tomato plants by feeding on their insect herbivores (Lins et al. 2014). If the pattern documented in tomato represents a general strategy, these results suggest that plants exposed to low R:FR ratios could minimize the cost of down-regulating direct defenses by finely adjusting the blend of volatile compounds that they emit in response to herbivory, turning themselves more attractive to prey-seeking carnivorous insects (Cortés et al. 2016).

\section{CHALLENGES AND OPPORTUNITIES}

The field of plant photobiology has come a long way since the pioneering attempts to connect plant responses to shade with the activity of phytochrome. During the last decade, research on the photoresponses of Arabidopsis seedlings, using hypocotyl elongation as the principal physiological readout, has been very successful in elucidating the main signalling components that connect photoreceptors (particularly phyB) with growth responses (Fig. 1). At the same time, research in other systems and conditions has revealed that photoreceptors modulate virtually all aspects of plant acclimation to varying light conditions in canopies. This modulation includes some responses that were never thought to be connected with light signalling, such as, for example, nutrient uptake and chemical communication between plants and other organisms (Fig. 2). The future of the field is full of opportunities and interesting challenges, some which are briefly outlined in the succeeding paragraphs.

\section{Dealing with complexity and signal interactions}

The light environment of plant canopies is complex and includes a multiplicity of shade signals. R:FR-centred research has proven to be highly successful in elucidating the main 
elements of the core SAS pathway. Nevertheless, the demonstration that even mutants that fail to respond to R:FR ratio show strong shade-avoidance responses to plant proximity (Keller et al. 2011) indicates that if the aim is to understand plant responses in nature, research will have to consider a broader array of light signals and photoreceptors. In addition, we know from physiological studies carried out more than four decades ago that the pathways activated by different photoreceptors often interact in the with each other (Mohr 1972). Since the signalling components downstream of individual photoreceptors have now been studied at an appreciable depth, it is becoming feasible to include them in signalling networks, which consider several photoreceptors and plant responses to light in a more integrative way (Hayes et al. 2014; Mazza \& Ballaré 2015; de Wit et al. 2016b; Goyal et al. 2016). This is highly important also when trying to translate knowledge on SAS control to crops in order to modulate (aspects of) shade avoidance; simply selecting against R:FR responses, for example, will not necessarily eliminate responses to light intensity or other proximity signals.

Complexity is not only a matter of multiple light colours but it is also a consequence of spatial and temporal variations in these light signals. Not all parts of a plant experience the exact same combination of light cues, and these light cues can be dynamic over time. This is usually not a problem if the goal is to understand a simple system, such as the Arabidopsis seedling, where there is little room for spatial variation in light quality, and the studied responses are complete in a very short period of time. But field studies with more mature plants indicate that many important photoresponses are locally controlled by the light environment of particular organs or parts. Examples include, among others, tillering responses in grasses (Deregibus et al. 1985), stem elongation in even-height canopies (Ballaré et al. 1990), leaf senescence (Rousseaux et al. 1996; Rousseaux et al. 1997) and reproductive abortion in soybean (Heindl \& Brun 1983). The modular nature of the plant body and the response to local light signals are essential aspects of plant photomorphogenesis.

A successful way to deal with the evident need for understanding the increasing complexity in biological research is to include computational modelling. This can be achieved at many different organizational levels. Functional structural plant models (FSP models) are a great tool to integrate a wide variety of physiological processes in a spatially explicit way, creating virtual plant stands in which parameters of plant growth can be modified. These parameters can include SAS in response to multiple light signals as occurring in these stands (Evers et al. 2007; Bongers et al. 2014). Computational models can also be used to understand interactions between light signals and resources (Hersch et al. 2014) or to predict functional responses to signalling gradients (van Berkel et al. 2013).

\section{Dealing with processes other than growth responses}

Given the historical focus on the effects of light on growth, it is not surprising that most of the efforts to elucidate downstream signalling pathways have concentrated on growth-related hormones, such as auxin, GA and BR. However, it has recently become clear that photoreceptors are major modulators of the hormonal pathways that control plant defence, including JA and SA. This modulation is sensitive to the changes in the light spectrum associated with neighbour proximity, which may have important implications for the regulation of defence responses in crops (Ballaré et al. 2012). Given the heightened interest in tradeoffs between plant growth and defence (Yang et al. 2012; Leone et al. 2014; Shyu \& Brutnell 2015; Campos et al. 2016; Cerrudo et al. 2017; Havko et al. 2016; Kliebenstein 2016; Smakowska et al. 2016), and the realization that photoreceptors play a key role feeding proximity information into the signalling mechanisms that make adaptive decisions in the face of these tradeoffs, we expect that a major challenge in future research will be to elucidate the mechanisms by which photoreceptors control defence signalling pathways.

\section{Translating to crops}

Whereas the mechanisms involved in the photocontrol of many important responses are now very well established, virtually nothing is known about the role of photoreceptors in controlling yield and defence-related traits in crops under field conditions. As the amount of information on molecular responses to light signals in cultivated species continues to grow (Kebrom \& Brutnell 2007; Bush et al. 2015; Horvath et al. 2015; Kharshiing \& Sinha 2015; Carriedo et al. 2017; Wang et al. 2016), the opportunities to manipulate those responses using traditional breeding, transformation, genome editing or other technologies will obviously increase. A major challenge will be to identify which responses should be manipulated in order to have a significant impact on crop yield, yield stability, crop health and/or plant quality. For example, it could be interesting to eliminate the effects of those light proximity signals that redirect resources to stem or petiole elongation at the expense of other desirable functions, such as plant defence. However, at the same time, it would be important to retain the ability of plant shoots to phototropically locate gaps in the crop canopy, in order to maximize light interception, or to adjust stomatal behaviour as a function of the prevailing light conditions, in order to optimize gas exchange. The recent progress in dissecting the signalling pathways that control specific decisions downstream of the photoreceptors provides an opportunity to target specific signalling elements so as to manipulate individual responses. For example, a step forward might be to uncouple defence responses from proximity perception in crop plants (Ballaré et al. 2012). Recent studies in Arabidopsis show that null mutations in $J A Z$ genes can reduce or eliminate the negative effect of low $\mathrm{R}: \mathrm{FR}$ ratios and phyB inactivation on plant immunity against necrotrophic pathogens and chewing insects, but without affecting morphological responses to shade signals (Cerrudo et al. 2012; Campos et al. 2016; Cerrudo et al. 2017). These findings hint at possible ways to develop crop plants that retain strong defence responses even when grown at high density. Refinement of technologies such as high-throughput sequencing and development of new model systems and genetic resources will surely help to identify targets for crop 
improvement. In a related vein, recent advances in artificial lighting technology, including the development of high-output LED arrays (Huché-Thélier et al. 2015; Demotes-Mainard et al. 2016), provide great potential for applying our increased understanding of plant photobiology to improve the yield, health and produce quality in horticultural crops.

\section{CONFLICT OF INTERESTS}

The authors have no conflicts of interest to declare.

\section{ACKNOWLEDGMENTS}

Research in our laboratories is financially supported by grants from CONICET (Consejo Nacional de Investigaciones Científicas y Técnicas), ANPCyT (Agencia Nacional de Promoción Científica y Tecnológica) and UBACyT (Universidad de Buenos Aires Ciencia y Técnica), to C.L.B., and grants from NWO (the Netherlands Organisation for Scientific Research), to R.P.

\section{REFERENCES}

Agrawal A., Kearney E., Hastings A. \& Ramsey T. (2012) Attenuation of the jasmonate burst, plant defensive traits, and resistance to specialist monarch caterpillars on shaded common milkweed (Asclepias syriaca). Journal of Chemical Ecology 38, 893-901.

Anten N.P.R., Casado-Garcia R. \& Nagashima H. (2005) Effects of mechanical stress and plant density on mechanical characteristics, growth, and lifetime reproduction of tobacco plants. American Naturalist 166, 650-660.

Ballaré C.L. (1999) Keeping up with the neighbours: phytochrome sensing and other signalling mechanisms. Trends in Plant Science 4, 97-102.

Ballaré C.L. (2014) Light regulation of plant defense. Annual Review of Plant Biology 65, 335-363.

Ballaré C.L., Barnes P.W., Flint S.D. \& Price S. (1995a) Inhibition of hypocotyl elongation by ultraviolet-B radiation in de-etiolating tomato seedlings. II. Time-course, comparison with flavonoid responses and adaptive significance. Physiologia Plantarum 93, 593-601.

Ballaré C.L., Mazza C.A., Austin A.T. \& Pierik R. (2012) Canopy light and plant health. Plant Physiology 160, 145-155.

Ballaré C.L., Sánchez R.A., Scopel A.L., Casal J.J. \& Ghersa C.M. (1987) Early detection of neighbour plants by phytochrome perception of spectral changes in reflected sunlight. Plant, Cell and Environment 10, 551-557.

Ballaré C.L., Scopel A.L., Radosevich S.R. \& Kendrick R.E. (1992) Phytochrome-mediated phototropism in de-etiolated seedlings. Plant Physiology 100, 170-177.

Ballaré C.L., Scopel A.L., Roush M.L. \& Radosevich S.R. (1995b) How plants find light in patchy canopies. A comparison between wild-type and phytochrome-B-deficient mutant plants of cucumber. Functional Ecology 9 , 859-868.

Ballaré C.L., Scopel A.L. \& Sanchez R.A. (1991) Photocontrol of stem elongation in plant neighbourhoods: effects of photon fluence rate under natural conditions of radiation. Plant, Cell and Environment 14, 57-65.

Ballaré C.L., Scopel A.L. \& Sánchez R.A. (1989) Photomodulation of axis extension in sparse canopies: role of the stem in the perception of light-quality signals of stand density. Plant Physiology 89, 1324-1330.

Ballaré C.L., Scopel A.L. \& Sánchez R.A. (1990) Far-red radiation reflected from adjacent leaves: an early signal of competition in plant canopies. Science $\mathbf{2 4 7}$ 329-332.

Barnes P.W., Flint S.D., Tobler M.A. \& Ryel R.J. (2016a) Diurnal adjustment in ultraviolet sunscreen protection is widespread among higher plants. Oecologia 181, 55-63.

Barnes P.W., Searles P.S., Ballaré C.L., Ryel R.J. \& Caldwell M.M. (2000) Non-invasive measurements of leaf epidermal transmittance of UV radiation using chlorophyll fluorescence: field and laboratory studies. Physiologia Plantarum 109, 274-283.
Barnes P.W., Tobler M.A., Keefover-Ring K., Flint S.D., Barkley A.E., Ryel R.J. \& Lindroth R.L. (2016b) Rapid modulation of ultraviolet shielding in plants is influenced by solar ultraviolet radiation and linked to alterations in flavonoids. Plant, Cell and Environment 39, 222-230.

Björkman O. (1981) Responses to different quantum flux densities. In Physiological Plant Ecology I (eds Lange O.L., Nobel P.S., Osmond C.B. \& Ziegler H.), pp. 57-107. Springer, Berlin Heidelberg.

Boccalandro H.E., De Simone S.N., Bergmann-Honsberger A., Schepens I., Fankhauser C. \& Casal J.J. (2008) Phytochrome kinase substrate1 regulates root phototropism and gravitropism. Plant Physiology 146, 108-115.

Boccalandro H.E., Giordano C.V., Ploschuk E.L., Piccoli P.N., Bottini R. \& Casal J.J. (2012) Phototropins but not cryptochromes mediate the blue light-specific promotion of stomatal conductance, while both enhance photosynthesis and transpiration under full sunlight. Plant Physiology 158, 1475-1484.

Boccalandro H.E., Rugnone M.L., Moreno J.E., Ploschuk E.L., Serna L., Yanovsky M.J. \& Casal J.J. (2009) Phytochrome B enhances photosynthesis at the expense of water-use efficiency in Arabidopsis. Plant Physiology 150, 1083-1092.

Bongers F.J., Evers J.B., Anten N.P. \& Pierik R. (2014) From shade avoidance responses to plant performance at vegetation level: using virtual plant modelling as a tool. New Phytologist 204, 268-272.

Boonman A., Prinsen E., Gilmer F., Schurr U., Peeters A.J.M., Voesenek L.A.C. J. \& Pons T.L. (2007) Cytokinin import rate as a signal for photosynthetic acclimation to canopy light gradients. Plant Physiology 143, 1841-1852.

Briggs W.R. \& Christie J.M. (2002) Phototropins 1 and 2: versatile plant blue-light receptors. Trends in Plant Science 7, 204-210.

Brown B.A. \& Jenkins G.I. (2008) UV-B signaling pathways with different fluence-rate response profiles are distinguished in mature Arabidopsis leaf tissue by requirement for UVR8, HY5, and HYH. Plant Physiology 146, 576-588.

Brütting C., Schäfer M., Vanková R., Gase K., Baldwin I.T. \& Meldau S. (2017) Changes in cytokinins are sufficient to alter developmental patterns of defense metabolites in Nicotiana attenuata. The Plant Journal 89, 15-30.

Bush S.M., Carriedo L., Daniel F., Ichihashi Y., Covington M.F., Kumar R., ... Maloof J.N. (2015) Auxin signaling is a common factor underlying natural variation in tomato shade avoidance. bioRxiv. DOI:10.1101/031088.

Campos M.L., Yoshida Y., Major I.T., de Oliveira Ferreira D., Weraduwage S.M., Froehlich J.E., ... Howe G.A. (2016) Rewiring of jasmonate and phytochrome B signalling uncouples plant growth-defense tradeoffs. Nature Communications 7, 12570125. DOI:10.11038/ncomms12570.

Cargnel M.D., Demkura P.V. \& Ballaré C.L. (2014) Linking phytochrome to plant immunity: low red : far-red ratios increase Arabidopsis susceptibility to Botrytis cinerea by reducing the biosynthesis of indolic glucosinolates and camalexin. New Phytologist 204, 342-354.

Carriedo L.G., Maloof J.N. \& Brady S.M. (2017) Molecular control of crop shade avoidance. Current Opinion in Plant Biology 30, 151-158.

Casal J.J. (2013) Photoreceptor signaling networks in plant responses to shade. Annual Review of Plant Biology 64, 403-427.

Casal J.J., Ballaré C.L., Tourn M. \& Sanchez R.A. (1994) Anatomy, growth and survival of a long-hypocotyl mutant of Cucumis sativus deficient in phytochrome b. Annals of Botany 73, 569-575.

Casson S.A., Franklin K.A., Gray J.E., Grierson C.S., Whitelam G.C. \& Hetherington A.M. (2009) phytochrome B and PIF4 regulate stomatal development in response to light quantity. Current Biology 19, 229-234.

Cerrudo I., Caliri-Ortiz M.E., Keller M.M., Degano M.E., Demkura P.V. \& Ballaré C.L. (2017) Exploring growth-defense tradeoffs in Arabidopsis. Phytochrome B inactivation requires JAZ10 to suppress plant immunity but not to trigger shade avoidance responses. Plant, Cell \& Environment . DOI:10.1111/ pce. 12877 .

Cerrudo I., Keller M.M., Cargnel M.D., Demkura P.V., de Wit M., Patitucci M.S., ... Ballaré C.L. (2012) Low red/far-red ratios reduce Arabidopsis resistance to Botrytis cinerea and jasmonate responses via a COI1-JAZ10-dependent, salicylic acid-independent mechanism. Plant Physiology 158, 2042-2052.

Cifuentes-Esquivel N., Bou-Torrent J., Galstyan A., Gallemí M., Sessa G., Salla M.M., ... Martínez-García J.F. (2013) The bHLH proteins BEE and BIM positively modulate the shade avoidance syndrome in Arabidopsis seedlings. The Plant Journal 75, 989-1002.

Ciolfi A., Sessa G., Sassi M., Possenti M., Salvucci S., Carabelli M., Morelli G. \& Ruberti I. (2013) Dynamics of the shade avoidance response in Arabidopsis thaliana. Plant Physiology 163, 331-353.

Cortés L.E., Weldegergis B.T., Boccalandro H.E., Dicke M. \& Ballaré C.L. (2016) Trading direct for indirect defense? Phytochrome B inactivation in tomato attenuates direct anti-herbivore defenses whilst enhancing volatile-mediated attraction of predators. New Phytologist 212, 1057-1071. 
Crocco C.D., Locascio A., Escudero C.M., Alabadí D., Blázquez M.A. \& Botto J F. (2015) The transcriptional regulator BBX24 impairs DELLA activity to promote shade avoidance in Arabidopsis thaliana. Nature Communications 6 , 6202.

Chehab E.Â.W., Yao C., Henderson Z., Kim S. \& Braam J. (2012) Arabidopsis touch-induced morphogenesis Is jasmonate mediated and protects against pests. Current Biology 22, 701-706.

Chehab E.W., Eich E. \& Braam J. (2009) Thigmomorphogenesis: a complex plant response to mechano-stimulation. Journal of Experimental Botany 60, 43-56.

Chen D., Xu G., Tang W., Jing Y., Ji Q., Fei Z. \& Lin R. (2013) Antagonistic basic helix-loop-helix/bZIP transcription factors form transcriptional modules that integrate light and reactive oxygen species signaling in Arabidopsis. The Plant Cell 25, 1657-1673.

Chen X., Yao Q., Gao X., Jiang C., Harberd N.P. \& Fu X. (2016) Shoot-to-root mobile transcription factor HY5 coordinates plant carbon and nitrogen acquisition. Current Biology 26, 640-646.

Chico J.-M., Fernández-Barbero G., Chini A., Fernández-Calvo P., Díez-Díaz M \& Solano R. (2014) Repression of jasmonate-dependent defenses by shade involves differential regulation of protein stability of MYC transcription factors and their JAZ repressors in Arabidopsis. The Plant Cell 26, 1967-1980.

Child R. \& Smith H. (1987) Phytochrome action in light-grown mustard: kinetics, fluence-rate compensation and ecological significance. Planta 172, 219-229.

Choi J., Huh S.U., Kojima M., Sakakibara H., Paek K.H. \& Hwang I. (2010) The cytokinin-activated transcription factor ARR2 promotes plant immunity via TGA3/NPR1-dependent salicylic acid signaling in Arabidopsis. Developmental Cell 19, 284-295.

Das D., St Onge K.R., Voesenek L.A.C.J., Pierik R. \& Sasidharan R. (2016) Ethylene- and shade-induced hypocotyl elongation share transcriptome patterns and functional regulators. Plant Physiology 172, 718-733.

de la Rosa T.M., Aphalo P.J. \& Lehto T. (1998) Effects of far-red light on the growth, mycorrhizas and mineral nutrition of Scots pine seedlings. Plant and Soil 201, 17-25.

de Lucas M., Daviere J.M., Rodriguez-Falcon M., Pontin M., Iglesias-Pedraz J. M., Lorrain S., ... Prat S. (2008) A molecular framework for light and gibberellin control of cell elongation. Nature 451, 480-484.

de Wit M., Galvão V.C. \& Fankhauser C. (2016a) Light-mediated hormonal regulation of plant growth and development. Annual Review of Plant Biology 67, 613-617.

de Wit M., Kegge W., Evers J.B., Vergeer-van Eijk M.H., Gankema P., Voesenek L.A. \& Pierik R. (2012) Plant neighbor detection through touching leaf tips precedes phytochrome signals. Proceedings of the National Academy of Sciences of the United States of America 109, 14705-14710.

de Wit M., Keuskamp D.H., Bongers F.J., Hornitschek P., Gommers C.M.M., Reinen E., ... Pierik R. (2016b) Integration of phytochrome and cryptochrome signals determines plant growth during competition for light. Current Biology 26, 3320-3326

de Wit M., Spoel S.H., Sanchez Perez G.F., Gommers C.M.M., Pieterse C.M.J., Voesenek L.A.C.J. \& Pierik R. (2013) Perception of low Red:Far-red ratio compromises both salicylic acid- and jasmonic acid- dependent pathogen defences in Arabidopsis. The Plant Journal 75, 90-103.

Demotes-Mainard S., Péron T., Corot A., Bertheloot J., Gourrierec J.L., Travier S., ... Sakr S. (2016) Plant responses to red and far-red lights, applications in horticulture. Environmental and Experimental Botany 121, 4-21.

Deregibus V.A., Sanchez R.A., Casal J.J. \& Trlica M.J. (1985) Tillering responses to enrichment of red light beneath the canopy in a humid natural grassland. Journal of Applied Ecology 22, 199-206.

Dervinis C., Frost C.J., Lawrence S.D., Novak N.G. \& Davis J.M. (2010) Cytokinin primes plant responses to wounding and reduces Insect performance. Journal of Plant Growth Regulation 29, 289-296.

Devlin P.F., Yanovsky M.J. \& Kay S.A. (2003) A genomic analysis of the shade avoidance response in Arabidopsis. Plant Physiology 133, 1617-1629.

Djakovic-Petrovic T., de Wit M., Voesenek L.A.C.J. \& Pierik R. (2007) DELLA protein function in growth responses to canopy signals. The Plant Journal $\mathbf{5 1}$ 117-126.

Dünser K. \& Kleine-Vehn J. (2015) Differential growth regulation in plants-the acid growth balloon theory. Current Opinion in Plant Biology 28, 55-59.

Engelen-Eigles G., Holden G., Cohen J.D. \& Gardner G. (2006) The effect of temperature, photoperiod, and light quality on gluconasturtiin concentration in watercress (Nasturtium officinale R. Br.). Journal of Agricultural and Food Chemistry 54, 328-334.

Evers J.B., Vos J., Chelle M., Andrieu B., Fournier C. \& Struik P.C. (2007) Simulating the effects of localized red:far-red ratio on tillering in spring wheat (Triticum aestivum) using a three-dimensional virtual plant model. New Phytologist 176, 325-336.
Favory J.J., Stec A., Gruber H., Rizzini L., Oravecz A., Funk M., ... Ulm R. (2009) Interaction of COP1 and UVR8 regulates UV-B-induced photomorphogenesis and stress acclimation in Arabidopsis. EMBO Journal 28, 591-601.

Feng S.H., Martinez C., Gusmaroli G., Wang Y., Zhou J.L., Wang F., ... Deng X. W. (2008) Coordinated regulation of Arabidopsis thaliana development by light and gibberellins. Nature 451, 475-479.

Flint S.D. \& Caldwell M.M. (1998) Solar UV-B and visible radiation in tropical forest gaps: measurements partitioning direct and diffuse radiation. Global Change Biology 4, 863-870.

Franklin K.A. \& Quail P.H. (2010) Phytochrome functions in Arabidopsis development. Journal of Experimental Botany 61, 11-24.

Fraser D.P., Hayes S. \& Franklin K.A. (2016) Photoreceptor crosstalk in shade avoidance. Current Opinion in Plant Biology 33, 1-7.

Galen C., Rabenold J.J. \& Liscum E. (2007) Functional ecology of a blue light photoreceptor: effects of phototropin-1 on root growth enhance drought tolerance in Arabidopsis thaliana. New Phytologist 173, 91-99.

Galstyan A., Cifuentes-Esquivel N., Bou-Torrent J. \& Martinez-Garcia J.F. (2011) The shade avoidance syndrome in Arabidopsis: a fundamental role for atypical basic helix-loop-helix proteins as transcriptional cofactors. The Plant Journal 66, 258-267.

González C.V., Ibarra S.E., Piccoli P.N., Botto J.F. \& Boccalandro H.E. (2012) Phytochrome $\mathrm{B}$ increases drought tolerance by enhancing ABA sensitivity in Arabidopsis thaliana. Plant, Cell and Environment 35, 1958-1968.

Goyal A., Karayekov E., Galvão V.C., Ren H., Casal J.J. \& Fankhauser C. (2016) Shade promotes phototropism through phytochrome B-controlled auxin production. Current Biology 26, 3280-3287.

Green T.R. \& Ryan C.A. (1972) Wound-induced proteinase inhibitor in plant leaves: A possible defense mechanism against insects. Science 175, 776-777.

Griebel T. \& Zeier J. (2008) Light regulation and daytime dependency of inducible plant defenses in Arabidopsis: Phytochrome signaling controls systemic acquired resistance rather than local defense. Plant Physiology 147, 790-801.

Gundel P.E., Pierik R., Mommer L. \& Ballaré C.L. (2014) Competing neighbors: light perception and root function. Oecologia 176, 1-10.

Harberd N.P., Belfield E. \& Yasumura Y. (2009) The Angiosperm gibberellinGID1-DELLA growth regulatory mechanism: how an "inhibitor of an inhibitor" enables flexible response to fluctuating environments. Plant Cell 21, 1328-1339.

Havko N., Major I., Jewell J., Attaran E., Browse J. \& Howe G.A. (2016) Control of carbon assimilation and partitioning by jasmonate: an accounting of growthdefense tradeoffs. Plants $\mathbf{5}, 7$.

Hayes S., Velanis C.N., Jenkins G.I. \& Franklin K.A. (2014) UV-B detected by the UVR8 photoreceptor antagonizes auxin signaling and plant shade avoidance. Proceedings of the National Academy of Sciences of the United States of America 111, 11894-11899.

Heindl J.C. \& Brun W.A. (1983) Light and shade effects on abscission and 14Cphotoassimilate partitioning among reproductive structures in soybean. Plant Physiology 73, 434-439.

Helber N., Wippel K., Sauer N., Schaarschmidt S., Hause B. \& Requena N. (2011) A versatile monosaccharide transporter that operates in the arbuscular mycorrhizal fungus Glomus sp is crucial for the symbiotic relationship with plants. Plant Cell 23, 3812-3823.

Hendricks S.B. \& Borthwick H.A. (1959) Photocontrol of plant development by the simultaneous excitations of two interconvertible pigments. Proceedings of the National Academy of Sciences of the United States of America 45, 344-349.

Hersch M., Lorrain S., de Wit M., Trevisan M., Ljung K., Bergmann S. \& Fankhauser C. (2014) Light intensity modulates the regulatory network of the shade avoidance response in Arabidopsis. Proceedings of the National Academy of Sciences of the United States of America 111, 6515-6520.

Hisamatsu T., King R.W., Helliwell C.A. \& Koshioka M. (2005) The involvement of gibberellin 20-oxidase genes in phytochrome-regulated petiole elongation of Arabidopsis. Plant Physiology 138, 1106-1116.

Hornitschek P., Kohnen M.V., Lorrain S., Rougemont J., Ljung K., LópezVidriero I., ... Fankhauser C. (2012) Phytochrome interacting factors 4 and 5 control seedling growth in changing light conditions by directly controlling auxin signaling. The Plant Journal 71, 699-711.

Hornitschek P., Lorrain S., Zoete V., Michielin O. \& Fankhauser C. (2009) Inhibition of the shade avoidance response by formation of non-DNA binding bHLH heterodimers. EMBO Journal 28, 3893-3902.

Horvath D.P., Hansen S.A., Moriles-Miller J.P., Pierik R., Yan C., Clay D.E., Scheffler B. \& Clay S.A. (2015) RNAseq reveals weed-induced PIF3-like as a candidate target to manipulate weed stress response in soybean. New Phytologist 207, 196-210. 
Hou X., Lee L.Y.C., Xia K., Yan Y. \& Yu H. (2010) DELLAs modulate jasmonate signaling via competitive binding to JAZs. Developmental Cell 19, 884-894.

Huché-Thélier L., Crespel L., Gourrierec J.L., Morel P., Sakr S. \& Leduc N. (2015) Light signaling and plant responses to blue and UV radiations-perspectives for applications in horticulture. Environmental and Experimental Botany 121, 22-38.

Izaguirre M.M., Mazza C.A., Astigueta M.S., Ciarla A.M. \& Ballaré C.L. (2013) No time for candy: passionfruit (Passiflora edulis) plants down-regulate damage-induced extra floral nectar production in response to light signals of competition. Oecologia 173, 213-221.

Izaguirre M.M., Mazza C.A., Biondini M., Baldwin I.T. \& Ballaré C.L. (2006) Remote sensing of future competitors: impacts on plant defenses. Proceedings of the National Academy of Sciences of the United States of America 103, 7170-7174.

Jenkins G.I. (2009) Signal transduction in responses to UV-B radiation. Annual Review of Plant Biology 60, 407-431.

Kang C.Y., Lian H.L., Wang F.F., Huang J.R. \& Yang H.Q. (2009) Cryptochromes, phytochromes, and COP1 regulate light-controlled stomatal development in arabidopsis. The Plant Cell 21, 2624-2641.

Kasperbauer M.J. (1971) Spectral distribution of light in a tobacco canopy and effects of end-of-day light quality on growth and development. Plant Physiology $\mathbf{4 7}, 775-778$.

Kasperbauer M.J. \& Hunt P.G. (1994) Shoot/root assimilate allocation and nodulation of Vigna unguiculata seedlings as influenced by shoot light environment. Plant and Soil 161, 97-101.

Kasperbauer M.J., Hunt P.G. \& Sojka R.E. (1984) Photosynthate partitioning and nodule formation in soybean plants that received red or far-red light at the end of the photosynthetic period. Physiologia Plantarum 61, 549-554.

Kebrom T.H. \& Brutnell T.P. (2007) The molecular analysis of the shade avoidance syndrome in the grasses has begun. Journal of Experimental Botany 58 3079-3089.

Kegge W., Ninkovic V., Glinwood R., Welschen R.A., Voesenek L.A. \& Pierik R. (2015) Red: far-red light conditions affect the emission of volatile organic compounds from barley (Hordeum vulgare), leading to altered biomass allocation in neighbouring plants. Annals of Botany 115, 961-970.

Kegge W. \& Pierik R. (2010) Biogenic volatile organic compounds and plant competition. Trends in Plant Science 15, 126-132.

Kegge W., Weldegergis B.T., Soler R., Eijk M.V.-V., Dicke M., Voesenek L.A.C.J. \& Pierik R. (2013) Canopy light cues affect emission of constitutive and methyl jasmonate-induced volatile organic compounds in Arabidopsis thaliana. New Phytologist 200, 861-874.

Keller M.M., Jaillais Y., Pedmale U.V., Moreno J.E., Chory J. \& Ballaré C.L. (2011) Cryptochrome 1 and phytochrome B control shade-avoidance responses in Arabidopsis via partially-independent hormonal cascades. The Plant Journal 67, 195-207.

Keuskamp D.H., Pollmann S., Voesenek L.A.C.J., Peeters A.J.M. \& Pierik R. (2010) Auxin transport through PIN-FORMED 3 (PIN3) controls shade avoidance and fitness during competition. Proceedings of the National Academy of Sciences of the United States of America 107, 22740-22744.

Keuskamp D.H., Sasidharan R., Vos I., Peeters A.J.M., Voesenek L.A.C.J. \& Pierik R. (2011) Blue light-mediated shade avoidance requires combined auxin and brassinosteroid action in Arabidopsis seedlings. The Plant Journal 67, 208-217.

Kharshiing E. \& Sinha S.P. (2015) Plant productivity: can photoreceptors light the way? Journal of Plant Growth Regulation 34, 206-214.

Kircher S. \& Schopfer P. (2012) Photosynthetic sucrose acts as cotyledon-derived long-distance signal to control root growth during early seedling development in Arabidopsis. Proceedings of the National Academy of Sciences of the United States of America 109, 11217-11221.

Kliebenstein D.J. (2016) False idolatry of the mythical growth versus immunity tradeoff in molecular systems plant pathology. Physiological and Molecular Plant Pathology 95, 55-59.

Kohnen M., Schmid-Siegert E., Trevisan M., Allenbach P.L., Sénéchal F., MüllerMoulé P., ... Fankhauser C. (2016) Neighbor detection induces organ-specific transcriptomes, revealing patterns underlying hypocotyl-specific growth. The Plant Cell . DOI:10.1105/tpc.1116.00463.

Kozuka T., Kobayashi J., Horiguchi G., Demura T., Sakakibara H., Tsukaya H. \& Nagatani A. (2010) Involvement of auxin and brassinosteroid in the regulation of petiole elongation under the shade. Plant Physiology 153, 1608-1618.

Kunihiro A., Yamashino T., Nakamichi N., Niwa Y., Nakanishi H. \& Mizuno T. (2011) PHYTOCHROME-INTERACTING FACTOR 4 and 5 (PIF4 and PIF5) activate the homeobox ATHB2 and auxin-inducible IAA29 genes in the coincidence mechanism underlying photoperiodic control of plant growth of Arabidopsis thaliana. Plant and Cell Physiology 52, 1315-1329.
Lee H.-J., Ha J.-H., Kim S.-G., Choi H.-K., Kim Z.H., Han Y.-J., ... Park C.-M. (2016) Stem-piped light activates phytochrome B to trigger light responses in Arabidopsis thaliana roots. Science Signaling 9, ra106-ra106.

Leivar P. \& Monte E. (2014) PIFs: systems integrators in plant development. The Plant Cell 26, 56-78.

Leivar P. \& Quail P.H. (2011) PIFs: pivotal components in a cellular signaling hub. Trends in Plant Science 16, 19-28.

Leivar P., Tepperman J.M., Cohn M.M., Monte E., Al-Sady B., Erickson E. \& Quail P.H. (2012) Dynamic antagonism between phytochromes and PIF family basic helix-loop-helix factors induces selective reciprocal responses to light and shade in a rapidly responsive transcriptional network in Arabidopsis. Plant Cell 24, 1398-1419.

Leone M., Keller M.M., Cerrudo I. \& Ballaré C.L. (2014) To grow or defend? Low red:far-red ratios reduce jasmonate sensitivity in Arabidopsis seedlings by promoting DELLA degradation and increasing JAZ10 stability. New Phytologist 204, 355-367.

Li J., Li G., Wang H. \& Wang D.X. (2011) Phytochrome signaling mechanisms. The Arabidopsis Book / American Society of Plant Biologists $9 \mathrm{e} 0148$.

Li L., Ljung K., Breton G., Schmitz R.J., Pruneda-Paz J., Cowing-Zitron C., ... Chory J. (2012) Linking photoreceptor excitation to changes in plant architecture. Genes \& Development 26, 785-790.

Lindblom K.L. (2015) Isolation of phytochrome, National Historic Chemical Landmarks program, pp. http://www.acs.org/content/acs/en/education/ whatischemistry/landmarks/isolation-of-phytochrome.html. American Chemical Society.

Lins J.C., Loon J.J.A., Bueno V.H.P., Lucas-Barbosa D., Dicke M. \& Lenteren J. C. (2014) Response of the zoophytophagous predators Macrolophus pygmaeus and Nesidiocoris tenuis to volatiles of uninfested plants and to plants infested by prey or conspecifics. BioControl 59, 707-718.

Lorrain S., Allen T., Duek P.D., Whitelam G.C. \& Fankhauser C. (2008) Phytochrome-mediated inhibition of shade avoidance involves degradation of growth-promoting bHLH transcription factors. The Plant Journal 53, 312-323.

Mazza C.A. \& Ballaré C.L. (2015) Photoreceptors UVR8 and phytochrome B cooperate to optimize plant growth and defense in patchy canopies. New Phytologist 207, 4-9.

Mazza C.A., Boccalandro H.E., Giordano C.V., Battista D., Scopel A.L. \& Ballaré C.L. (2000) Functional significance and induction by solar radiation of ultraviolet-absorbing sunscreens in field-grown soybean crops. Plant Physiology 122, 117-125.

Millenaar F.F., Van Zanten M., Cox M.C.H., Pierik R., Voesenek L.A.C.J. \& Peeters A.J.M. (2009) Differential petiole growth in Arabidopsis thaliana: photocontrol and hormonal regulation. New Phytologist 184, 141-152.

Mohr H. (1972) Lectures on Photomorphogenesis. Springer-Verlag, Berlin.

Morales L.O., Brosché M., Vainonen J., Jenkins G.I., Wargent J.J., Sipari N., ... Aphalo P.J. (2013) Multiple roles for UV RESISTANCE LOCUS8 in regulating gene expression and metabolite accumulation in arabidopsis under solar ultraviolet radiation. Plant Physiology 161, 744-759.

Moreno J.E., Tao Y., Chory J. \& Ballaré C.L. (2009) Ecological modulation of plant defense via phytochrome control of jasmonate sensitivity. Proceedings of the National Academy of Sciences of the United States of America 106, 4935-4940.

Morgan D.C. \& Smith H. (1978) The relationship between phytochromephotoequilibrium and development in light grown Chenopodium album L. Planta 142, 187-193.

Mullen J.L., Weinig C. \& Hangarter R.P. (2006) Shade avoidance and the regulation of leaf inclination in Arabidopsis. Plant, Cell and Environment 29, 1099-1106.

Nagata M., Yamamoto N., Shigeyama T., Terasawa Y., Anai T., Sakai T., ... Suzuki A. (2015) Red/far red light controls arbuscular mycorrhizal colonization via jasmonic acid and strigolactone signaling. Plant and Cell Physiology 56, 2100-2109.

Pecháčková S. (1999) Root response to above-ground light quality - differences between rhizomatous and non-rhizomatous clones of Festuca rubra. Plant Ecology 141, 67-77.

Pedmale U.V., Huang S.S.C., Zander M., Cole B.J., Hetzel J., Ljung K., , .. Chory J. (2016) Cryptochromes interact directly with pifs to control plant growth in limiting blue light. Cell 164, 233-245.

Pierik R., Cuppens M.L.C., Voesenek L.A.C.J. \& Visser E.J.W. (2004a) Interactions between ethylene and gibberellins in phytochrome-mediated shade avoidance responses in tobacco. Plant Physiology 136, 2928-2936.

Pierik R. \& de Wit M. (2014) Shade avoidance: phytochrome signalling and other aboveground neighbour detection cues. Journal of Experimental Botany $\mathbf{6 5}$, 2815-2824. 
Pierik R., Djakovic-Petrovic T., Keuskamp D.H., de Wit M. \& Voesenek L.A.C.J. (2009) Auxin and ethylene regulate elongation responses to neighbor proximity signals independent of gibberellin and DELLA proteins in Arabidopsis. Plant Physiology 149, 1701-1712.

Pierik R. \& Testerink C. (2014) The art of being flexible: how to escape from shade, salt, and drought. Plant Physiology 166, 5-22.

Pierik R., Whitelam G.C., Voesenek L.A.C.J., de Kroon H. \& Visser E.J.W. (2004b) Canopy studies on ethylene-insensitive tobacco identify ethylene as a novel element in blue light and plant-plant signalling. The Plant Journal 38, 310-319.

Poorter H., Niklas K.J., Reich P.B., Oleksyn J., Poot P. \& Mommer L. (2012) Biomass allocation to leaves, stems and roots: meta-analyses of interspecific variation and environmental control. New Phytologist 193, 30-50.

Procko C., Burko Y., Jaillais Y., Ljung K., Long J.A. \& Chory J. (2016) The epidermis coordinates auxin-induced stem growth in response to shade. Genes and Development 30, 1529-1541.

Procko C., Crenshaw C.M., Ljung K., Noel J.P. \& Chory J. (2014) Cotyledon-generated auxin is required for shade-induced hypocotyl growth in brassica rapa. Plant Physiology 165, 1285-1301.

Roig-Villanova I., Bou-Torrent J., Galstyan A., Carretero-Paulet L., Portolés S., Rodríguez-Concepción M. \& Martínez-García J.F. (2007) Interaction of shade avoidance and auxin responses: a role for two novel atypical bHLH proteins. EMBO Journal 26, 4756-4767.

Rose J.K.C., Braam J., Fry S.C. \& Nishitani K. (2002) The XTH family of enzymes involved in xyloglucan endotransglucosylation and endohydrolysis: current perspectives and a new unifying nomenclature. Plant and Cell Physiology 43, 1421-1435.

Ross A.F. (1961) Systemic acquired resistance induced by localized virus infections in plants. Virology 14, 340-358.

Rousseaux M.C., Ballaré C.L., Jordan E.T. \& Vierstra R.D. (1997) Directed overepression of PHYA locally suppresses stem elongation and leaf senescence responses to far-red radiation. Plant, Cell and Environment 20, $1551-1558$

Rousseaux M.C., Hall A.J. \& Sánchez R.A. (1996) Far-red enrichment and photosynthetically active radiation level influence leaf senescence in fieldgrown sunflower. Physiologia Plantarum 96, 217-224.

Sage L.C. (1992) CHAPTER 26 - Shade avoidance. In Pigment of the Imagination, pp. 371-394. Academic Press, Boston.

Salisbury F.J., Hall A., Grierson C.S. \& Halliday K.J. (2007) Phytochrome coordinates Arabidopsis shoot and root development. The Plant Journal 50, 429-438.

Salter M.G., Franklin K.A. \& Whitelam G.C. (2003) Gating of the rapid shadeavoidance response by the circadian clock in plants. Nature 426, 680-683.

Sasidharan R., Keuskamp D.H., Kooke R., Voesenek L.A. \& Pierik R. (2014) Interactions between auxin, microtubules and XTHs mediate green shadeinduced petiole elongation in Arabidopsis. PloS One 9e90587.

Sasidharan R., Voesenek L.A. \& Pierik R. (2011) Cell wall modifying proteins mediate plant acclimatization to biotic and abiotic stresses. Critical Reviews in Plant Sciences 30, 548-562.

Schmitt J., Dudley S.A. \& Pigliucci M. (1999) Manipulative approaches to testing adaptive plasticity: phytochrome-mediated shade-avoidance responses in plants. The American Naturalist 154, S43-S54.

Schmitt J., McCormac A.C. \& Smith H. (1995) A test of the adaptive plasticity hypothesis using transgenic and mutant plants disabled in phytochrome-mediated elongation responses to neighbors. American Naturalist 146, 937-953.

Sellaro R., Crepy M., Trupkin S.A., Karayekov E., Buchovsky A.S., Rossi C. \& Casal J.J. (2010) Cryptochrome as a sensor of the blue/green ratio of natural radiation in Arabidopsis. Plant Physiology 154, 401-409.

Sessa G., Carabelli M., Sassi M., Ciolfi A., Possenti M., Mittempergher F., ... Ruberti I. (2005) A dynamic balance between gene activation and repression regulates the shade avoidance response in Arabidopsis. Genes \& Development 19, 2811-2815.

Shyu C. \& Brutnell T.P. (2015) Growth-defence balance in grass biomass production: the role of jasmonates. Journal of Experimental Botany 66, 4165-4176.
Skálová H. \& Vosátka M. (1998) Growth response of three Festuca rubra clones to light quality and arbuscular mycorrhiza. Folia Geobotanica 33, 159-169.

Smakowska E., Kong J., Busch W. \& Belkhadir Y. (2016) Organ-specific regulation of growth-defense tradeoffs by plants. Current Opinion in Plant Biology 29, 129-137.

Smith H. (1982) Light quality, photoperception, and plant strategy. Annual Review of Plant Physiology 33, 481-518.

Smith H. (1995) Physiological and ecological function within the phytochrome family. Annual Review of Plant Physiology and Plant Molecular Biology 46, 289-315.

Smith H. \& Whitelam G.C. (1997) The shade avoidance syndrome: multiple responses mediated by multiple phytochromes. Plant, Cell and Environment 20, 840-844.

Sorin C., Salla-Martret M., Bou-Torrent J., Roig-Villanova I. \& Martinez-Garcia J.F. (2009) ATHB4, a regulator of shade avoidance, modulates hormone response in Arabidopsis seedlings. The Plant Journal 59, 266-277.

Steindler C., Matteucci A., Sessa G., Weimar T., Ohgishi M., Aoyama T., Morelli G. \& Ruberti I. (1999) Shade avoidance responses are mediated by the ATHB2 HD-zip protein, a negative regulator of gene expression. Development 126, 4235-4245.

Suzuki A., Suriyagoda L., Shigeyama T., Tominaga A., Sasaki M., Hiratsuka Y., ... Hirsch A.M. (2011) Lotus japonicus nodulation is photomorphogenetically controlled by sensing the red/far red (R/FR) ratio through jasmonic acid (JA) signaling. Proceedings of the National Academy of Sciences of the United States of America 108, 16837-16842.

Tao Y., Ferrer J.L., Ljung K., Pojer F., Hong F., Long J.A., ... Chory J. (2008) Rapid synthesis of auxin via a new tryptophan-dependent pathway is required for shade avoidance in plants. Cell 133, 164-176.

Tester M. \& Morris C. (1987) The penetration of light through soil. Plant, Cell \& Environment 10, 281-286.

Toledo-Ortiz G., Johansson H., Lee K.P., Bou-Torrent J., Stewart K., Steel G., Rodríguez-Concepción M. \& Halliday K.J. (2014) The HY5-PIF regulatory module coordinates light and temperature control of photosynthetic gene transcription. PLoS Genetics 10e1004416.

Tong H., Leasure C.D., Hou X., Yuen G., Briggs W. \& He Z.H. (2008) Role of root UV-B sensing in Arabidopsis early seedling development. Proceedings of the National Academy of Sciences of the United States of America 105, 21039-21044.

Trupkin S.A., Legris M., Buchovsky A.S., Rivero M.B.T. \& Casal J.J. (2014) Phytochrome B nuclear bodies respond to the low red to far-red ratio and to the reduced irradiance of canopy shade in arabidopsis. Plant Physiology 165, 1698-1708.

Ulm R. \& Jenkins G. (2015) Q\&A: how do plants sense and respond to UV-B radiation? BMC Biology $\mathbf{1 3}, 45$.

van Berkel K., de Boer R.J., Scheres B. \& ten Tusscher K. (2013) Polar auxin transport: models and mechanisms. Development 140, 2253-2268.

Viczian A., Klose C., Ádám É. \& Nagy F. (2016) New insights of red light-induced development. Plant, Cell \& Environment . DOI:10.1111/pce.12880.

Wang H., Wu G., Zhao B., Wang B., Lang Z., Zhang C. \& Wang H. (2016) Regulatory modules controlling early shade avoidance response in maize seedlings. BMC Genomics 17, 1-16.

Whitelam G.C. \& Johnson C.B. (1980) Phytochrome control of nitrate reductase activity and anthocyanin synthesis in light-grown Sinapis alba (L.). Differential responses of cotyledons and hypocotyls. The New Phytologist 85, 475-482.

Yang D.-L., Yao J., Mei C.-S., Tong X.-H., Zeng L.-J., Li Q., ... He S.Y. (2012) Plant hormone jasmonate prioritizes defense over growth by interfering with gibberellin signaling cascade. Proceedings of the National Academy of Sciences of the United States of America 109, E1192-E1200.

Yu J., Qiu H., Liu X., Wang M., Gao Y., Chory J. \& Tao Y. (2015) Characterization of $t u b 4^{P 287 L}$, a $\beta$-tubulin mutant, revealed new aspects of microtubule regulation in shade. Journal of Integrative Plant Biology 57, 757-769.

Received 9 November 2016; received in revised form 10 January 2017; accepted for publication 13 January 2017 